\title{
Tingkat Prediksi Pendaftar Ujian Kompetensi Laboratorium Menggunakan Metode Least Square
}

\author{
Gunadi $^{\mathrm{a}}$, Julius Santony ${ }^{\mathrm{b}}$, Jufriadif Na'am ${ }^{\mathrm{c}}$ \\ Universitas Putra Indonesia YPTK Padang \\ agunadi36@gmail.com, bjuliussantony@yahoo.co.id, cjufriadifnaam@gmail.com
}

\begin{abstract}
Services for laboratory competency test participants must be increased for each period. With the number of participants fluctuating, the laboratory must prepare and predict how many facilities will be used to support these activities, such as laboratory rooms, exam questions, and other equipment. To overcome this problem, a method is needed to predict the number of participants in the coming period. In this study, the Least Square method is used to predict participants in the next period. This method managed to get the number of predictions in the coming period with a prediction error rate of 9.99\% using the Mean Absolute Percentage Error (MAPE). The empirical results show that this research is very helpful for the laboratory in preparing laboratory competence examination facilities.
\end{abstract}

Keywords: Laboratory facilities, Predictions, Least Square, Registrants, Competency Exams

\begin{abstract}
Abstrak
Pelayanan terhadap peserta ujian kompetensi laboratorium setiap periode harus ditingkatkan. Dengan berfluktuasinya jumlah perserta, maka pihak laboratorium harus mempersiapkan fasilitas, seperti ruangan, soal ujian, dan peralatan lainya. Dengan permasalahan tersebut, dibutuhkan suatu metode yang dapat memprediksi jumlah pendaftar pada periode akan datang. Metode Least Square digunakan untuk memprediksi pendaftar ujian kompetensi laboratorium pada periode berikutnya. Hasil dari pengujian metode ini berhasil mendapatkan jumlah prediksi pada periode yang akan datang dengan tingkat kesalahan prediksi diukur dengan Mean Absolute Percentage Error (MAPE) sebesar 9,99\%. Sehingga penelitian ini sangat membantu pihak laboratorium dalam mempersiapkan fasilitas ujian kompetensi laboratorium.
\end{abstract}

Kata kunci: fasilitas laboratorium, prediksi, least square, pendaftar, ujian kompetensi

(C) 2018 Jurnal RESTI

\section{Pendahuluan}

Ujian kompetensi laboratorium diadakan setiap periode. Jumlah peserta pendaftar selalu berfluktuasi sehingga pihak laboratorium sulit menentukan segala kebutuhan ujian. Kebutuhan ujian kompetensi laboratorium ini berupa ruangan, soal ujian dan peralatan pendukung.

Sehubungan dengan hal yang diuraikan sebelumnya maka diperlukan sistem yang dapat memprediksi jumlah pendaftar ujian kompetensi laboratorium pada periode yang akan datang. Algoritma dapat digunakan untuk memecahkan masalah dan memproses informasi yang diperoleh sebagai hasil dari pengamatan atas proses fisik [1]. Prediksi adalah alat penting untuk membuat suatu perencanaan [2]. Setiap model prediksi yang berbeda memiliki kelebihan dan kekurangan masing-masing [3]. Prediksi atau peramalan ialah meramalkan hal yang akan terjadi dimasa depan dengan memanfaatkan macam-macam informasi yang mendukung atau data historis dengan menggunakan perhitungan metode ilmiah [4]. Prediksi atau peramalan harus dilakukan dengan perhitungan yang matang agar hasil peramalan mendapatkan hasil yang sesuai dengan harapan dan hasil yang diramalkan akurat. Untuk menghidari resiko, maka dibutuhkan teknik peramalan yang akurat [5].

Prediksi jumlah pendaftar ujian kompetensi laboratorium dimasa yang akan datang dapat menggunakan metode Least Square. Metode Least Square (Kuadrat Terkecil) merupakan salah satu metode berupa data deret berkala yang mana dibutuhkan data-data dimasa lampau untuk melakukan peramalan dimasa mendatang sehingga dapat ditentukan hasilnya [6]. Sangat penting untuk menggunakan data historis dengan menetapkan model matematis yang tepat agar dapat dijadikan informasi yang berguna [7]. Metode Least Square merupakan

Diterima Redaksi : 27-08-2018 | Selesai Revisi : 06-11-2018 | Diterbitkan Online : 16-12-2018 
teknik pengoptimalan matematika [8]. Persamaan menjadi terarah dan sesuai dengan tujuan pada matematis dibentuk oleh metode kuadrat terkecil [9]. penelitian ini terlihat pada Gambar 1.

Jadi metode least square merupakan metode yang digunakan untuk melakukan suatu prediksi dengan memanfaatkan data histori masa lalu untuk dijadikan pedoman dimasa depan.

Ada beberapa penelitian yang telah dilakukan untuk memprediksi dengan menggunakan metode least square. Penelitian yang dilakukan Hariri F R(2016) membahas tentang permasalahan penjualan yang setiap harinya mengalami naik turun dan mengakibatkan pengadaan bahan baku tidak sesuai dengan hasil penjualan sehingga menyebabkan kerugian maka diperlukan prediksi menggunakan metode least square. Sedangkan pada penelitian yang dilakukan oleh Mulyani D(2015) membahas permasalahan tentang memprediksi jumlah siswa baru untuk periode mendatang menggunakan metode least square. Pada penelitian yang dilakukan oleh Suwita L(2018) membahas permasalahan tentang persaingan pasar sehingga diperlukan perencanaan dan penargetan penjualan dimasa mendatang agar dapat bersaing dipasaran menggunakan metode least square [10].

Pada penelitian yang dilakukan oleh A. Restu A(2017) membahas permasalahan tentang prediksi hasil sadap karet menggunakan data sebelumnya dengan menggunakan metode least square agar dijadikan pendukung keputusan dalam mengambil keputusan [11]. Sedangkan penelitian yang dilakukan oleh Manurung B U P(2015) membahas tentang prediksi penjualan sepeda motor dimasa yang akan datang menggunakan metode least square sehingga dapat mempersiapkan kebutuhan jumlah sepeda motor dimasa yang akan datang [12]. Sedangkan pada penelitian yang dilakukan oleh Simbolon T M(2016) membahas permasalahan prediksi jumlah pertumbuhan penduduk pada Kecamatan Tebing Tinggi dengan menggunakan metode least square sehingga dapat mengetahui pertumbuhan penduduk dimasa yang akan datang[13].

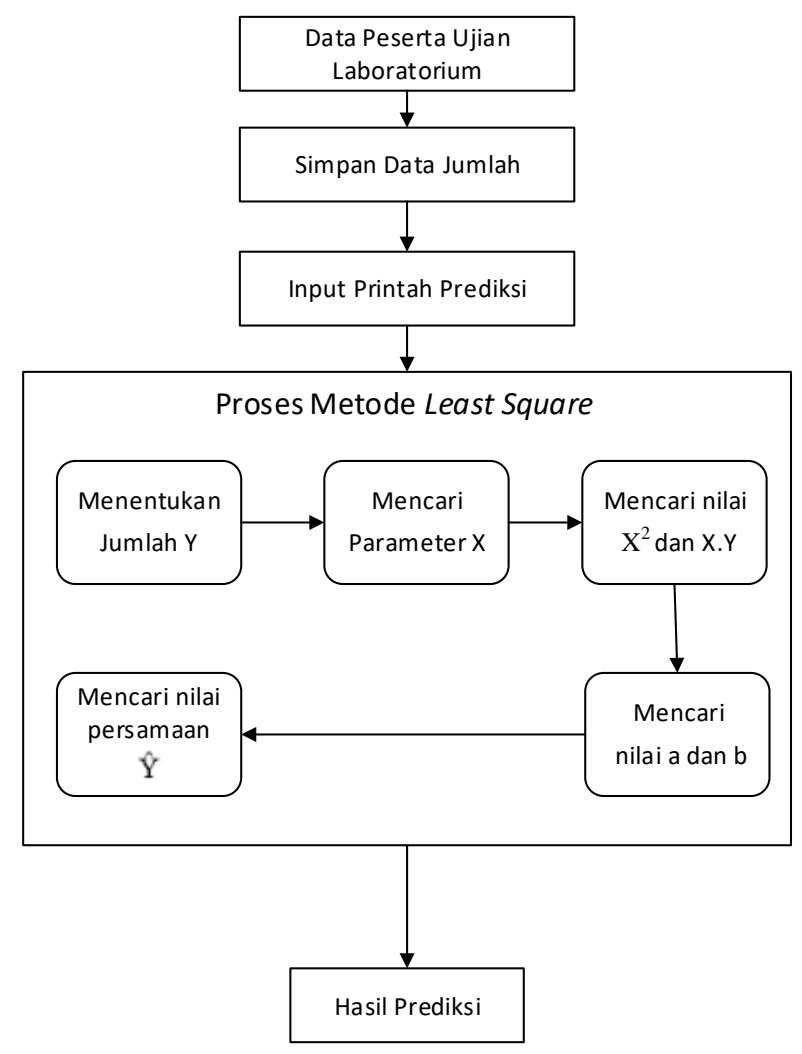

Gambar 1. Kerangka Kerja Prediksi Metode Least Square

Uraian kerangka kerja metode least square untuk memprediksi pada Gambar 1 akan dijelaskan sebagai berikut:

\subsection{Data Jumlah Peserta Ujian}

Pada tahap ini dilakukan pengumpulan data. Proses pengumpulan data yang dibutuhkan dalam penelitian ini dilakukan dengan cara melakukan pengambilan data di Laboratorium Komputer STMIK Amik Riau. Data yang diambil berupa data jumlah peserta ujian Dari permasalahan dan penelitian yang dilakukan kompetensi tahun ajaran 2013/2014 sampai tahun sebelumnya maka penulis tertarik membuat penelitian 2017/2018. Penulis mendapatkan data dari database untuk memprediksi jumlah pendaftar ujian kompetensi sistem untuk menunjang penelitian ini.

laboratorium diperiode yang akan datang dengan menggunakan data jumlah pendaftar ujian kompetensi yang sebelumnya sehingga mempermudah laboran Pada tahapan ini akan dilakukan proses penginputan untuk mempersiapkan segala kebutuhan untuk ujian data hasil pengumpulan data ke sistem yang akan kompetensi laboratorium seperti ruangan, soal ujian diolah. Data yang disimpan ke sistem prediksi ini dan peralatan yang akan digunakan.

\section{Metodologi Penelitian}

Pada tahap metodologi penelitian akan diuraikan tentang metode yang digunakan dalam penelitian yang tercakup dalam kerangka kerja metode least square. Tahap-tahap kerangka kerja bertujuan agar penelitian berupa jumlah pendaftar, tahun dan id ujian laboratorium.

\subsection{Input Perintah Prediksi}

Pada tahapan ini pengguna sistem akan melakukan penginputan perintah ke sistem. Kemudian sistem dapat melakukan proses prediksi menggunakan metode least square dengan beberapa tahapan proses yang ada. 


\subsection{Proses Prediksi dengan Metode Least Square}

Pada tahap ini akan dilakukan analisa terhadap metode yang digunakan dimulai dari mempelajari tahapan- pembahasan dari penelitian. Penjelasan hasil dan tahapan dalam metode least square. Tahapan dalam pembahasan penelitian ini sebagai berikut: metode ini harus dilakukan secara bertahap. Adapun tahapan dalam metode ini akan dijelaskan sebagai berikut:

a. Tentukan data jumlah pendaftar (Y)

b. Tentukan parameter $\mathrm{X}$

Dalam menentukan parameter $\mathrm{X}$ jika jumlah data genap maka nilai $X$ yang digunakan $-5,-3$ $1,1,3,5$ dan seterusnya tergantung jumlah data , sedangkan data ganjil 3,-2,-1,0,1,2,3 dan seterusnya.

c. Tentukan nilai $X^{2}$ dan X.Y

Nilai $X^{2}$ didapatkan dari hasil nilai $X$ dikuadratkan. Sedangkan untuk nilai X.Y merupakan perkalian dari nilai $\mathrm{X}$ dengan Nilai Y.

d. Buat persamaan trend nilai a dan nilai $b$ Untuk mencari persamaan trend $\mathrm{a}$ dan $\mathrm{b}$ dengan rumus berikut:

$a=\frac{\sum Y}{n}$
$b=\frac{\sum Y \cdot X}{\sum X^{2}}$

Dimana :

$$
\begin{array}{ll}
\Sigma \mathrm{Y} & =\text { Total jumlah aktual dari } \mathrm{Y} \\
\mathrm{n} & =\text { Jumlah data } \\
\Sigma \mathrm{Y} . \mathrm{X} & =\text { Total jumlah perkalian } \mathrm{X} \text { dan } \mathrm{Y} \\
\Sigma \mathrm{X}^{2} & =\text { Total jumlah kuadrat dari } \mathrm{X} \\
a & =\text { Nilai trend pada tahun dasar } \\
b & =\text { Rata-rata pertumbuhan nilai trend } \\
& \text { pada tiap tahun }
\end{array}
$$

e. Menentukan nilai permsamaan trend "Ŷ"

Untuk mencari permasamaan trend $\hat{Y}$ dengan rumus berikut:

$\hat{\mathrm{Y}}=\mathrm{a}+\mathrm{b} .(\mathrm{X})$

Dimana

$\hat{\mathrm{Y}}=$ nilai veriabel terikat (dependent variabel).

$a=$ Nilai trend pada tahun dasar

$b=$ Rata-rata pertumbuhan nilai trend pada tiap tahun

$\mathrm{X}=$ nilai variabel bebas (independent variabel).

\subsection{Hasil Prediksi}

Pada tahap ini maka akan dihasilkan hasil dari prediksi yang sudah diolah menggunakan perhitungan metode least square. Pada tahap ini juga akan dilakukan pengamatan dan analisa terhadap hasil implementasi metode least square dalam memprediksi jumlah pendaftar ujian kompetensi laboratorium kemudian menarik kesimpulan terhadap hasil prediksi yang dihasilkan melalui perhitungan metode least square.

\section{Hasil dan Pembahasan}

\subsection{Data}

Adapun data uji yang digunakan dalam penelitian ini terlihat pada Tabel 1.

Tabel 1. Data Pendaftar Ujian Kompetensi Laboratorium

\begin{tabular}{cllc}
\hline No & Tahun & Semester & Jumlah Pendaftar (Orang) \\
\hline 1 & $2013 / 2014$ & Ganjil & 220 \\
2 & $2013 / 2014$ & Genap & 221 \\
3 & $2014 / 2015$ & Ganjil & 245 \\
4 & $2014 / 2015$ & Genap & 297 \\
5 & $2015 / 2016$ & Ganjil & 238 \\
6 & $2015 / 2016$ & Genap & 245 \\
7 & $2016 / 2017$ & Ganjil & 178 \\
8 & $2016 / 2017$ & Genap & 196 \\
9 & $2017 / 2018$ & Ganjil & 228 \\
10 & $2017 / 2018$ & Genap & 160 \\
\hline
\end{tabular}

\subsection{Penerapan Metode Least Square}

1. Perhitungan Prediksi Jumlah Pendaftar Tahun 2016/2017 Semester Genap

Tabel 2. Data Pendaftar Ujian 2013/2014 sampai Ganjil 2016/2017

\begin{tabular}{crccccc}
\hline No & Tahun & Semester & Y & X & $X^{2}$ & X.Y \\
\hline 1 & $2013 / 2014$ & Ganjil & 220 & -3 & 9 & -660 \\
2 & $2013 / 2014$ & Genap & 221 & -2 & 4 & -442 \\
3 & $2014 / 2015$ & Ganjil & 245 & -1 & 1 & -245 \\
4 & $2014 / 2015$ & Genap & 297 & 0 & 0 & 0 \\
5 & $2015 / 2016$ & Ganjil & 238 & 1 & 1 & 238 \\
6 & $2015 / 2016$ & Genap & 245 & 2 & 4 & 490 \\
7 & $2015 / 2016$ & Genap & 178 & 3 & 9 & 534 \\
\multicolumn{2}{l}{ Jumlah } & n=7 & 1644 & 0 & 28 & -85 \\
\hline
\end{tabular}

Dimana:

$a=\frac{\sum Y}{n}=\frac{1644}{7}=234,8571$

$b=\frac{\sum Y \cdot X}{\sum X^{2}}=\frac{-85}{28}=-3,0357$

Persamaan trend menjadi:

$$
\begin{aligned}
\hat{\mathrm{Y}} & =\mathrm{a}+\mathrm{b} .(\mathrm{X}) \\
& =234,8571+(-3,0357 * 4) \\
& =222,7143
\end{aligned}
$$

Untuk prediksi jumlah pada tahun sebelumnya maka nilai $\mathrm{X}$ untuk mendapatkan nilai prediksi menggunakan nilai $X$ yang sudah ditentukan pada Tabel 2. Berikut ini merupakan hasil prediksi pada periode sebelumnya terlihat pada Tabel 3 . 
Tabel 3. Data Perbandingan Hasil Prediksi Dengan Data Sebenarnya

\begin{tabular}{cccccc}
\hline No & Tahun & Semester & $\begin{array}{c}\text { Jumlah } \\
\text { Pendaftar }\end{array}$ & $\begin{array}{c}\text { Least } \\
\text { Square }\end{array}$ & $\begin{array}{c}\text { Persenta } \\
\text { se }\end{array}$ \\
\hline 1 & $2013 / 2014$ & Ganjil & 220 & 244 & $90 \%$ \\
2 & $2013 / 2014$ & Genap & 221 & 241 & $92 \%$ \\
3 & $2014 / 2015$ & Ganjil & 245 & 238 & $97 \%$ \\
4 & $2014 / 2015$ & Genap & 297 & 235 & $79 \%$ \\
5 & $2015 / 2016$ & Ganjil & 238 & 232 & $97 \%$ \\
6 & $2015 / 2016$ & Genap & 245 & 229 & $93 \%$ \\
7 & $2016 / 2017$ & Ganjil & 178 & 226 & $79 \%$ \\
8 & $2016 / 2017$ & Genap & 220 & 223 & $88 \%$ \\
\hline
\end{tabular}

Setelah mendapatkan hasil dari prediksi jumlah pendaftar ujian kompetensi pada semester Genap 2016/2017 dapat dilihat pada Tabel 3 persentase kecocokan hasil prediksi dengan data sebenarnya sebesar $88 \%$.

2. Perhitungan Prediksi Jumlah Pendaftar Tahun 2017/2018 Semester Genap

Tabel 4. Data Pendaftar Ujian 2014/2015 sampai Ganjil 2017/2018

\begin{tabular}{ccccccc}
\hline No & Tahun & Semester & Y & X & $X^{2}$ & X.Y \\
\hline 1 & $2014 / 2015$ & Ganjil & 245 & -3 & 9 & -735 \\
2 & $2014 / 2015$ & Genap & 297 & -2 & 4 & -594 \\
3 & $2015 / 2016$ & Ganjil & 238 & -1 & 1 & -238 \\
4 & $2015 / 2016$ & Genap & 245 & 0 & 0 & 0 \\
5 & $2016 / 2017$ & Ganjil & 178 & 1 & 1 & 178 \\
6 & $2016 / 2017$ & Genap & 196 & 2 & 4 & 392 \\
7 & $2017 / 2018$ & Ganjil & 228 & 3 & 9 & 684 \\
\multicolumn{2}{l}{ Jumlah } & n=7 & 1627 & 0 & 28 & -313 \\
\hline
\end{tabular}

Dimana:

$$
\begin{aligned}
& a=\frac{\sum Y}{n}=\frac{1627}{7}=232,4286 \\
& b=\frac{\sum Y . X}{\sum X^{2}}=\frac{-313}{28}=-11,1786
\end{aligned}
$$

Persamaan trend menjadi:

$$
\begin{aligned}
\hat{\mathrm{Y}} & =\mathrm{a}+\mathrm{b} .(\mathrm{X}) \\
& =232,4286+(-11,1786 * 4) \\
& =187,7143
\end{aligned}
$$

Untuk prediksi jumlah pada tahun sebelumnya maka nilai X untuk mendapatkan nilai prediksi menggunakan nilai $X$ yang sudah ditentukan pada Tabel 4 dan berikut ini merupakan hasil prediksi pada periode sebelumnya.

Tabel 5. Data Perbandingan Hasil Prediksi Dengan Data Sebenarnya

\begin{tabular}{cclccc}
\hline No & Tahun & Semester & $\begin{array}{c}\text { Jumlah } \\
\text { Pendaftar }\end{array}$ & $\begin{array}{c}\text { Least } \\
\text { Square }\end{array}$ & $\begin{array}{c}\text { Persenta } \\
\text { se }\end{array}$ \\
\hline 1 & $2014 / 2015$ & Ganjil & 245 & 265 & $92 \%$ \\
2 & $2014 / 2015$ & Genap & 297 & 254 & $87 \%$ \\
3 & $2015 / 2016$ & Ganjil & 238 & 243 & $98 \%$ \\
4 & $2015 / 2016$ & Genap & 245 & 232 & $95 \%$ \\
5 & $2016 / 2017$ & Ganjil & 178 & 221 & $80 \%$ \\
6 & $2016 / 2017$ & Genap & 196 & 210 & $93 \%$ \\
7 & $2017 / 2018$ & Ganjil & 228 & 199 & $87 \%$ \\
8 & $2017 / 2018$ & Genap & 160 & 188 & $85 \%$ \\
\hline
\end{tabular}

Setelah mendapatkan hasil dari prediksi jumlah pendaftar ujian kompetensi pada semester Genap 2016/2017 dapat dilihat pada Tabel 5 persentase kecocokan hasil prediksi dengan data sebenarnya sebesar $85 \%$.

3. Perhitungan Prediksi Jumlah Pendaftar Tahun 2018/2019 Semester Ganjil

Tabel 6. Data Pendaftar Ujian Genap 2014/2015 sampai 2017/2018

\begin{tabular}{ccccccc}
\hline No & Tahun & Semester & Y & X & $X^{2}$ & X.Y \\
\hline 1 & $2014 / 2015$ & Genap & 297 & -3 & 9 & -891 \\
\hline 2 & $2015 / 2016$ & Ganjil & 238 & -2 & 4 & -476 \\
3 & $2015 / 2016$ & Genap & 245 & -1 & 1 & -245 \\
4 & $2016 / 2017$ & Ganjil & 178 & 0 & 0 & 0 \\
5 & $2016 / 2017$ & Genap & 196 & 1 & 1 & 196 \\
6 & $2017 / 2018$ & Ganjil & 228 & 2 & 4 & 456 \\
7 & $2017 / 2018$ & Genap & 160 & 3 & 9 & 480 \\
\multicolumn{2}{l}{ Jumlah } & n=7 & 1542 & 0 & 28 & -480 \\
\hline
\end{tabular}

Dimana:

$a=\frac{\sum Y}{n}=\frac{1542}{7}=220,2857$

$b=\frac{\sum Y \cdot X}{\sum X^{2}}=\frac{-480}{28}=-17,1429$

Persamaan trend menjadi:

$$
\begin{aligned}
\hat{\mathrm{Y}} & =\mathrm{a}+\mathrm{b} .(\mathrm{X}) \\
& =220,2857+(-17,1429 * 4) \\
& =151,7143
\end{aligned}
$$

Jumlah prediksi pada semester Ganjil 2018/2019 berjumlah 152 Pendaftar. Untuk prediksi jumlah pada tahun sebelumnya maka nilai $\mathrm{X}$ untuk mendapatkan nilai prediksi menggunakan nilai $X$ yang sudah ditentukan pada Tabel 6 dan berikut ini merupakan hasil prediksi pada periode sebelumnya terlihat pada Tabel 7.

Tabel 7. Data Perbandingan Hasil Prediksi Dengan Data Sebenarnya

\begin{tabular}{cccccc}
\hline No & Tahun & Semester & $\begin{array}{c}\text { Jumlah } \\
\text { Pendaftar }\end{array}$ & $\begin{array}{c}\text { Least } \\
\text { Square }\end{array}$ & $\begin{array}{c}\text { Persenta } \\
\text { se }\end{array}$ \\
\hline 1 & $2014 / 2015$ & Genap & 297 & 272 & $91 \%$ \\
\hline 2 & $2015 / 2016$ & Ganjil & 238 & 255 & $93 \%$ \\
3 & $2015 / 2016$ & Genap & 245 & 237 & $97 \%$ \\
4 & $2016 / 2017$ & Ganjil & 178 & 220 & $81 \%$ \\
5 & $2016 / 2017$ & Genap & 196 & 203 & $96 \%$ \\
6 & $2017 / 2018$ & Ganjil & 228 & 186 & $82 \%$ \\
7 & $2017 / 2018$ & Genap & 160 & 169 & $95 \%$ \\
\hline
\end{tabular}

Karena pada periode yang akan datang semester Ganjil 2018/2019 merupakan masa mendatang maka pengukuran kesalahan prediksi menggunakan Mean Absolute Percentage Error (MAPE). Berikut pengukuran kesalahan prediksinya terlihat pada Tabel 8 . 
Tabel 8. Analisa Kesalahan Prediksi Semester Ganjil 2018/2019

\begin{tabular}{cccccc}
\hline No & Tahun & $\begin{array}{c}\text { Semest } \\
\text { er }\end{array}$ & $\begin{array}{c}\text { Jumlah } \\
(\mathrm{Y} 1)\end{array}$ & $\begin{array}{c}\text { Prediksi } \\
(\mathrm{Yt})\end{array}$ & $(\mathrm{Y} 1 \mathrm{Yt}) / \mathrm{Y} 1$ \\
\hline 1 & $2014 / 2015$ & Genap & 297 & 25 & 0.0851 \\
\hline 2 & $2015 / 2016$ & Ganjil & 107 & -17 & 0.0696 \\
3 & $2015 / 2016$ & Genap & 382 & 8 & 0.0309 \\
4 & $2016 / 2017$ & Ganjil & 146 & -42 & 0.2376 \\
5 & $2016 / 2017$ & Genap & 274 & -7 & 0.0364 \\
6 & $2017 / 2018$ & Ganjil & 282 & 42 & 0.1842 \\
7 & $2017 / 2018$ & Genap & 135 & -9 & 0.0554 \\
& $\Sigma$ & & & & 0.6992 \\
\hline
\end{tabular}

Berikut ini merupakan penentuan erorr prediksi dengan menggunakan Mean Absolute Percentace Error (MAPE) adalah sebagai berikut :

$$
\begin{aligned}
\text { MAPE } & =\frac{\sum \frac{|Y 1-Y t|}{Y 1}}{n} \times 100 \% \\
& =\frac{\sum 0,6992}{7} \times 100 \% \\
& =9,99 \%
\end{aligned}
$$

Maka perhitungan errornya prediksi pada semester Ganjil 2018/2019 sebesar 9,99\%. Dengan nilai error prediksi yang semakin kecil maka hasil prediksinya semakin akurat. Sehingga metode least square dapat digunakan untuk prediksi jumlah pendaftar ujian kompetensi dimasa datang.

\subsection{Implementasi}

Pada bagian ini dijelaskan mengenai hasil dari implementasi sistem yang telah dilakukan. Berikut merupakan tampilan beberapa hasil implementasi sistem dalam proses prediksi.

\section{Prediksi Semester Genap 2016/2017(20162)}

Dalam menentukan hasil prediksi ini digunakan data dari semester Ganjil 2013/2014(20131) sampai Ganjil 2016/2017(20161). Hasil implementasi sistem terlihat pada Gambar 2.

Dari Gambar 2 dapat dijelaskan merupakan tahapan metode least square dalam melakukan perhitungan untuk menentukan prediksi. Berikut penjelasannya:

a. Nilai $n$ adalah jumlah data yang digunakan.

b. Nilai a merupakan nilai trend dari tahun dasar.

c. Nilai b merupakan rata-rata pertumbuhan trend pada setiap tahun.

d. Nilai $\hat{Y}$ merupakan nilai veriabel terikat (dependent variabel).

Dimana:

$$
\begin{aligned}
& \mathrm{n}=7 \\
& a=\frac{\sum Y}{n} \quad=\frac{1644}{7}=234,8571
\end{aligned}
$$

$$
b=\frac{\sum Y \cdot X}{\sum X^{2}}=\frac{-85}{28}=-3,0357
$$

Persamaan trend menjadi:

$$
\begin{aligned}
\hat{\mathrm{Y}} & =\mathrm{a}+\mathrm{b} .(\mathrm{X}) \\
& =234,8571+(-3,0357 * 4) \\
& =222,7143
\end{aligned}
$$

Sehingga didapatkan dari nilai $\hat{Y}$ merupakan prediksi pada tahun 20162 sebesar 223 pendaftar.

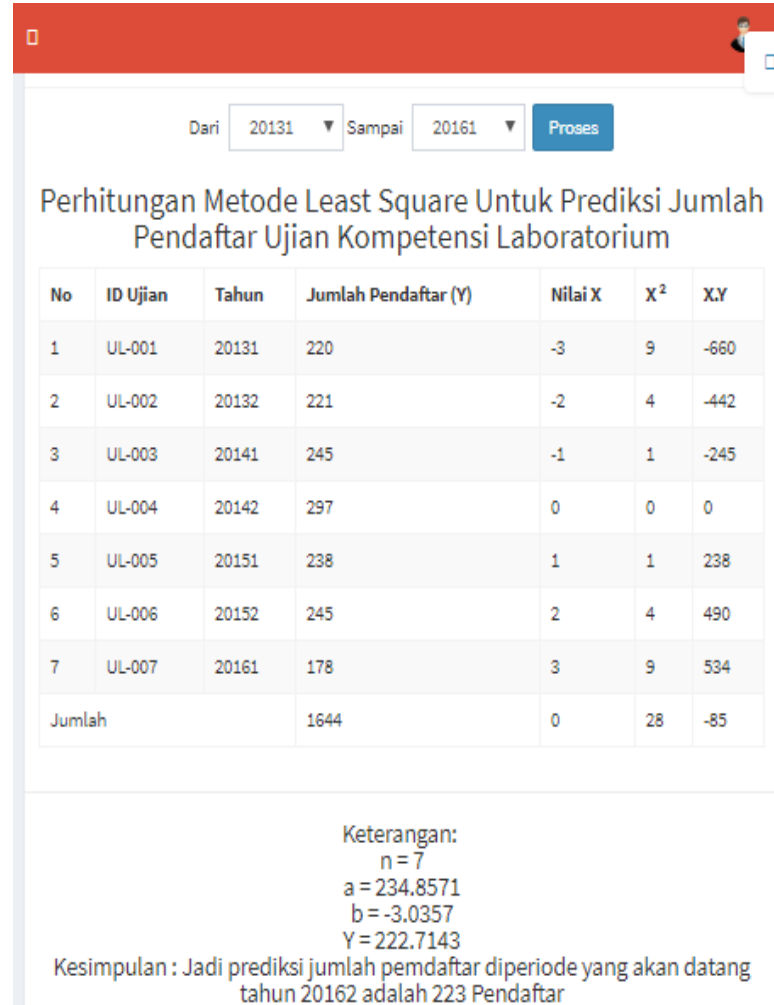

Gambar 2. Hasil Prediksi Genap 2016/2017 (20162)

\section{Prediksi Semester Genap 2017/2018 (20172)}

Dalam menentukan hasil prediksi ini digunakan data dari semester Ganjil 2014/2015(20141) sampai Ganjil 2017/2018(20171). Hasil implementasi sistem terlihat pada Gambar 3.

Dari Gambar 3 dapat dijelaskan merupakan tahapan metode least square dalam melakukan perhitungan untuk menentukan prediksi. Berikut penjelasannya:

a. Nilai $n$ adalah jumlah data yang digunakan.

b. Nilai a merupakan nilai trend dari tahun dasar.

c. Nilai b merupakan rata-rata pertumbuhan trend pada setiap tahun.

d. Nilai $\hat{Y}$ merupakan nilai veriabel terikat (dependent variabel).

Dimana:

$$
\begin{aligned}
& \mathrm{n}=7 \\
& a=\frac{\sum Y}{n} \quad=\frac{1627}{7}=232,4286
\end{aligned}
$$




$$
b=\frac{\sum Y \cdot X}{\sum X^{2}}=\frac{-313}{28}=-11,1786
$$

Persamaan trend menjadi:

$$
\begin{aligned}
\hat{\mathrm{Y}} & =\mathrm{a}+\mathrm{b} .(\mathrm{X}) \\
& =232,4286+(-11,1786 * 4) \\
& =187,7143
\end{aligned}
$$

Sehingga didapatkan dari nilai $\hat{Y}$ merupakan prediksi pada tahun 20172 sebesar 188 pendaftar.

\begin{tabular}{|c|c|c|c|c|c|c|}
\hline No & ID Ujian & Tahun & Jumlah Pendaftar ( $(Y)$ & Nilai X & $x^{2}$ & $X . Y$ \\
\hline 1 & UL-003 & 20141 & 245 & -3 & 9 & -735 \\
\hline 2 & UL-004 & 20142 & 297 & -2 & 4 & -594 \\
\hline 3 & UL-005 & 20151 & 238 & -1 & 1 & -238 \\
\hline 4 & UL-006 & 20152 & 245 & 0 & 0 & 0 \\
\hline 5 & UL-007 & 20161 & 178 & 1 & 1 & 178 \\
\hline 6 & UL-008 & 20162 & 196 & 2 & 4 & 392 \\
\hline 7 & UL-009 & 20171 & 228 & 3 & 9 & 684 \\
\hline \multicolumn{3}{|c|}{ Jumlah } & 1627 & 0 & 28 & -313 \\
\hline
\end{tabular}

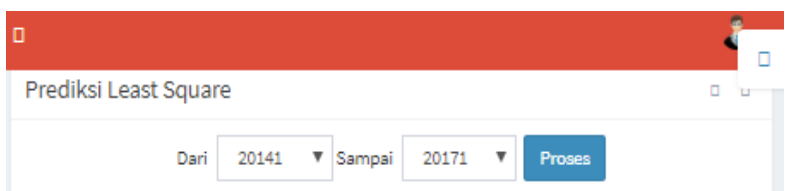

Perhitungan Metode Least Square Untuk Prediksi Jumlah Pendaftar Ujian Kompetensi Laboratorium

$$
\begin{gathered}
\text { Keterangan: } \\
\mathrm{n}=7 \\
\mathrm{a}=232.4286 \\
\mathrm{~b}=-11.1786 \\
\mathrm{Y}=187.7143 \\
\text { Kesimpulan : Jadi prediksi jumlah pemdaftar diperiode yang akan datang } \\
\text { tahun 20172 adalah 188 Pendaftar }
\end{gathered}
$$

Gambar 3. Hasil Prediksi Genap 2017/2018(20172)

\section{Prediksi Semester Ganj1 2018/2019(20181)}

Dalam menentukan hasil prediksi ini digunakan data dari semester Ganjil 2014/2015(20141) sampai Ganjil 2017/2018(20171). Hasil implementasi sistem terlihat pada Gambar 4.

Dari Gambar 4 dapat dijelaskan merupakan tahapan metode least square dalam melakukan perhitungan untuk menentukan prediksi. Berikut penjelasannya:

a. Nilai $n$ adalah jumlah data yang digunakan.

b. Nilai a merupakan nilai trend dari tahun dasar.

c. Nilai b merupakan rata-rata pertumbuhan trend pada setiap tahun.

d. Nilai $\hat{Y}$ merupakan nilai veriabel terikat (dependent variabel).

Dimana:

$\mathrm{n}=7$

$$
\begin{aligned}
& a=\frac{\sum Y}{n}=\frac{1542}{7}=220,2857 \\
& b=\frac{\sum Y \cdot X}{\sum X^{2}}=\frac{-480}{28}=-17,1429
\end{aligned}
$$

Persamaan trend menjadi:

$$
\begin{aligned}
\hat{\mathrm{Y}} & =\mathrm{a}+\mathrm{b} .(\mathrm{X}) \\
& =220,2857+(-17,1429 * 4) \\
& =151,7143
\end{aligned}
$$

Sehingga didapatkan dari nilai $\hat{Y}$ merupakan prediksi jumlah pendaftar pada tahun 20181 sebesar 152 pendaftar.

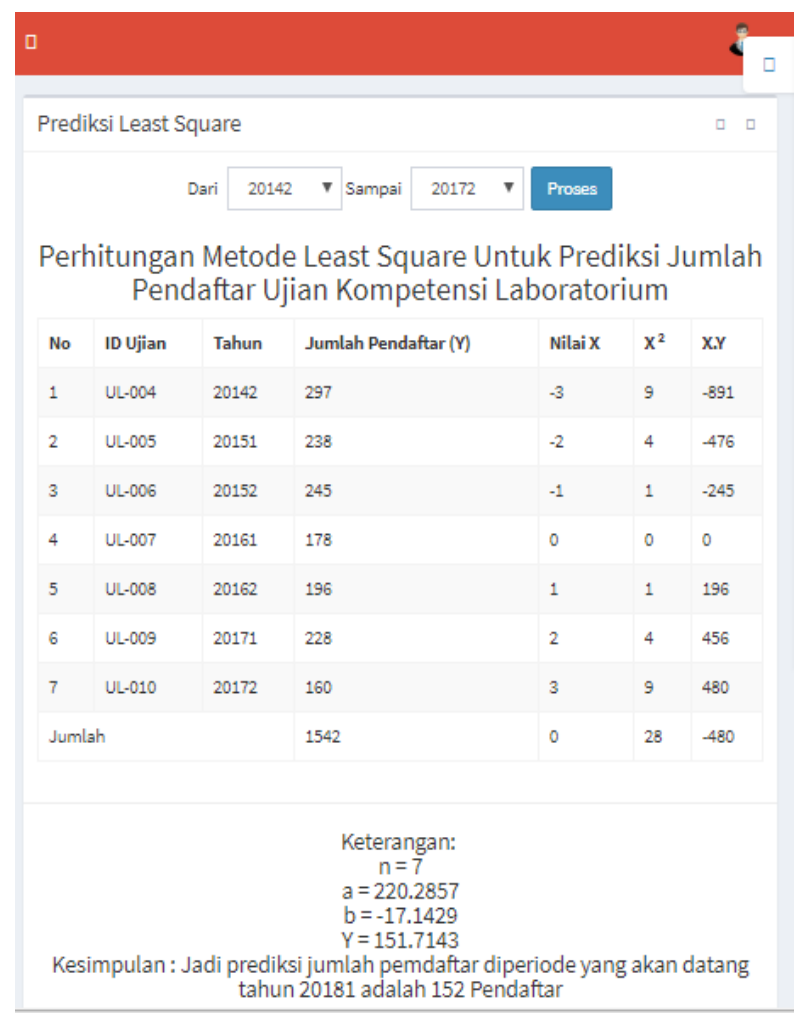

Gambar 4. Hasil Prediksi Ganjil 2018/2019(20181)

Dari hasil implementasi didapatkan hasil melalui tahapan perhitungan metode least square yang terlihat pada Gambar 2, Gambar 3 dan Gambar 4 sesuai dengan perhitungan manual pada uraian sebelumnya yaitu pada bagian penerapan metode least square.

\section{Kesimpulan}

Dari hasil penerapan metode Least Square dalam memprediksi jumlah pendaftar ujian kompetensi laboratorium dimasa akan datang diketahui sistem yang dibangun dapat memberikan informasi jumlah pendaftar yang mungkin akan terjadi pada periode selanjutnya dengan tingkat kesalahan prediksi diukur dengan Mean Absolute Percentage Error (MAPE) sebesar 9,99\%. Hasil prediksi ini dapat digunakan sebagai informasi dalam mendukung pengambilan

Jurnal RESTI (Rekayasa Sistem dan Teknologi Informasi) Vol . 2 No. 3 (2018) 746 - 752 
keputusan dan persiapan kebutuhan dalam pelaksanaan ujian kompetensi laboratorium pada periode akan datang.

\section{Daftar Rujukan}

[1] Smagin V I., 2017. Prediction Of States Of Discrete Systems With Unknown Input Of The Model Using Compensation. Russian Physics Journal, 59(9), pp.1507-1514. DOI: 10.1007/s11182-017-0937-6.

[2] Mulyani D., 2015. Prediction of New Student Numbers Using Least Square Method. International Journal of Advanced Research in Artificial Intelligence, 4(5), pp.30-35. DOI: 10.14569/issn.2165-4069.

[3] Fengmei Y., Meng L., Anqiang H. and Jian L., 2014. Forcasting Time Series With Genetic Programming Based On Least Square. Journal of Systems Science and Complexity, pp.117-129. DOI: 10.1007/s11424-014-3295-2.

[4] Wanto A. and Windarto A P., 2017. Analisis Prediksi Indeks Harga Konsumen Berdasarkan Kelompok Kesehatan Dengan Menggunakan Metode Backpropagation. Jurnal Sinkron, pp.3749. ISSN: 2541-2019.

[5] Guntur M., Santony J. and Yuhandri, 2018. Prediksi Harga Emas dengan Menggunakan Metode Naïve Bayes dalam Investasi untuk Meminimalisasi Resiko. Jurnal Resti, pp. 354-360. ISSN: 2580-0760.

[6] Hariri F R., 2016. Metode Least Square Untuk Prediksi Penjualan Sari Kedelai ROSI. Jurnal SIMETRIS, 7(2). ISSN: 2252-4983.
[7] Zhang Z., Yuan S., Xu Z. and Fang L., 2013. A Prediction Method about Central Heating Parameters Based on Method of Least Square. International Conference on Measurement, Information and Control, pp.1163-1166. DOI: 10.1109/MIC.2013.6758165.

[8] Chi H., 2015. A Discussions on the Least-Square Method in the Course of Error Theory and Data Processing. International Conference on Computational Intelligence and Communication Networks A, pp.486-489. DOI : 10.1109/CICN.2015.100.

[9] Ge L., Ye S Y., Shan S T., Zhu S H., Wan H. and Fan S. 2015., The Model of PK/PD for Danhong Injection Analyzed by Least Square Method. International Conference on Information Technology in Medicine and Education, pp.292-296. DOI: 10.1109/ITME.2015.47.

[10] Suwita L., 2018. Metode Least Square Dalam Mengukur Trend Penjualan Pada Home Industry Bengkel Sendal Thostee Bukittinggi. Jurnal Menara Ilmu, pp.54-60. ISSN: 1693-2617.

[11]A Restu R., 2017. Penerapan Metode Least Square Untuk Prediksi Hasil Sadap Karet. Jurnal PROGRESIF, pp.1569-1576. ISSN: 0216-3284.

[12]Manurung B U P., 2015. Implementasi Least Square Dalam Untuk Prediksi Penjualan Sepeda Motor (Studi Kasus: PT.Graha Auto Pratama). Jurnal Riset Komputer, pp.21-24. ISSN: 2407389X.

[13]Simbolon T M., 2016. Perancangan Aplikasi Forecasting Pertumbuhan Penduduk Pada Kecamatan Tebing Tinggi Dengan Menggunakan Metode Least Square. Jurnal Riset Komputer, pp.78-83. ISSN: 2407-389X. 